\title{
EL DESPLAZAMIENTO ESPACIAL DEL PROYECTO LITERARIO DE SALVADOR ELIZONDO: DE "SILA" A EL MAR DE IGUANAS
}

\author{
Norma Angélica Cuevas Velasco \\ Universidad Veracruzana, México \\ ncuevas@uv.mx
}

\begin{abstract}
Resumen: Este artículo propone la recuperación del primer cuento publicado por Salvador Elizondo: "Sila" y, teniéndolo como principio de lectura, proyecta una forma posible de ejecutar la noción de espacio más allá de sus posibilidades topológicas, a la manera de la noción de espacio literario propuesta por Maurice Blanchot. Las tres partes que integran el artículo buscan valorar las distintas funciones que desempeña la modalidad descriptiva (espacialidad / poeticidad) en un discurso escritural que linda con la poesía sin abandonar la prosa, cuyo sello tonal y estilístico es el rodeo del relato sin definirse categóricamente como narración. El comentario del cuento empuja un distingo entre el paisaje realista y el paisaje imaginario; este arco pretende descubrir para el lector una suerte de puesta en crisis de la narratividad, la cual es extensiva al tema de la transgenericidad (hibridez), con lo que se da paso a la reflexión sobre la relación de la escritura con la vida, más que con la realidad, de allí que la escritura íntima (cuadernos y diarios, por ejemplo) sea el espacio literario donde la poética de la obra y el pensamiento literario del autor acontecen como fenómenos susceptibles de ser descritos.
\end{abstract}

Palabras clave: lugares, paisajes, espacio literario, cuerpo, poética.

\section{SPATIAL DISPLACEMENT IN SALVADOR ELIZONDO'S LITERARY PROJECT: FROM "SILA" TO EL MAR DE IGUANAS}

\begin{abstract}
This article proposes the recovery of the first short story published by Salvador Elizondo: "Sila", considering which as a principle of reading, projects a possible way to execute the notion of space beyond its topological possibilities, as a notion of literary space as it is proposed by Maurice Blanchot. The three parts that build the article are seeking to assess the different functions performed by the descriptive mode (spatiality / poeticity) in a scriptural discourse that borders on poetry without abandoning prose, and whose tonal and stylistic stamp is the detour of the story without being defined categorically as narration. The commentary on the story pushes a distinction between the realistic landscape and the imaginary landscape. This arch tries to discover for the reader a kind of crisis of narrativity, which is extensive to the theme of transgenericity (hybridity), and which gives way to a reflection on the relationship between writing and life, more that between writing and reality, that is why intimate writing (notebooks and diaries, for example) is the literary space where the poetics of the author's work and literary thought occur as phenomena that can be described.
\end{abstract}


Keywords: places, landscapes, literary space, body, poetics.

DOI: https://doi.org/10.24029/lejana.2018.11.254

Recibido: el 26 de mayo de 2018

Aceptado: el 15 de julio de 2018

Publicado: el 22 de octubre de 2018 


\section{"Sila", el primer cuento de Salvador Elizondo}

Hace cincuenta y seis años que Salvador Elizondo dibujó el espacio de lo que, al paso del tiempo, vendríamos a observar como su geografía mental: el espacio literario al que jamás renunciaría y en torno al cual organizará su vida entera, que no es otra sino la del grafógrafo. La circunstancia que da origen a esta historia podría narrarse más o menos así: en octubre de 1962, la Revista de la Universidad de México publica el número dos del volumen XVII; entonces la dirección de la publicación la ocupaba Jaime García Terres y el equipo de redacción lo integraban Juan García Ponce, Juan Vicente Melo, José Emilio Pacheco y Carlos Valdés. Esta revista era patrocinada por el Banco de Comercio Exterior, la Unión Nacional de Productores de Azúcar, la Financiera Nacional Azucarera, la Asociación de Ingenieros Civiles, la Nacional Financiera y el Banco Nacional de México, por lo cual no era extraño leer, además de colaboraciones de creación y crítica literaria, textos académicos de interés social o antropológico. En este número se incluyó el artículo titulado "El combate contra la pobreza en América Latina" de la autoría de Josué de Castro y, entre otros, uno de Francisco Ayala: "Realismo y barroco". Las páginas 14, 15 y 16 del citado número de la Revista de la Universidad de México las ocupó un cuento abrumadoramente rulfiano por cuanto hace la forma de su elocución; se trata de "Sila", un cuento ilustrado con dibujos hechos por el propio Salvador Elizondo. Hasta donde tengo noticia, este cuento no fue recuperado por su autor en la reunión de su obra; tampoco las ediciones de El Colegio Nacional lo han rescatado hasta ahora; la única reproducción apareció, sin los errores dactilográficos del original, en el año 2012, en la revista Letras Libres, para conmemorar el medio siglo de su publicación.

He querido destacar el carácter misceláneo de la Revista de la Universidad de México, porque me interesa tener presente que Elizondo es un autor raro o excéntrico respecto al gusto estético que predominó en los autores mexicanos de la década de los sesenta y, sobre todo, de las precedentes, que no frente a los escritores de la llamada Generación de la Casa del Lago o del Medio Siglo con la que históricamente la crítica lo identifica. Elizondo discrepó con la estética nacionalista (regionalista, mexicana, hispanoamericana o latinoamericana) y defendió la idea de que la escritura - que no puede ser otra más que literaria — debe buscar la belleza rompiendo los límites del género, pues es tal vez este camino de libertad la única vía posible para lograr acercarse a lo propio, a aquello no reductible a determinados temas o asuntos sociales, políticos o ideológicos; sino el estilo con que en la escritura se construyen mundos susceptibles de ser recibidos como reales y cercanos durante la lectura que realice cualquier lector, de cualquier época. El arte debe poner sus ojos en el futuro, no en el pasado. Otra razón para considerar el número completo de la revista en cuestión es porque para Elizondo eso pudo ser determinante en la recepción del cuento, si consideramos lo que escribió cuando iba a aparecer otro de sus cuentos, este sí recuperado en sus Obras:

Mañana sale "Mnemothreptos" en Plural. Creo que va a ser mi primer magno fracaso. Está bien. Ahora lo que necesito es fracasar en algo para dar un paso adelante en la escritura. [...] Nunca he tenido tanta curiosidad por saber cómo reacciona la gente ante una obra literaria. Creo que voy en buena compañía en este número, con Ulalume y con Cuevas et al. En fin. A ver qué pasa [...]. (2015: 196) 
Esta cita corresponde a la entrada del domingo 14 de noviembre de 1971, de sus Diarios; para entonces "Sila" tenía casi una década de haber sido publicado.

¿Por qué su primer cuento quedará en la sombra, como escritura al margen de la Obra? ¿Por qué entonces emular el estilo de Juan Rulfo y publicar "Sila”? ¿Podría leerse este fenómeno como una salutación $y$, al mismo tiempo, como el distanciamiento de la literatura mexicana de esos años que ya reclamaba por todos lados una nueva dirección que no fuera el entorno de la Revolución Mexicana? ¿Acaso Elizondo expresó en ese cuento lo que ya tenía claro sobre el arte en general, que, para trascender la atemporalidad, los referentes todos debían ensancharse tanto hasta tocar la ausencia? Mientras no conozcamos todos los cuadernos escritos por Elizondo, mientras desconozcamos todas las páginas de sus diarios no podemos sino especular, atisbar quizá algunas posibilidades que funden el principio de una conjetura. Como se ve, no me dirijo hacia la respuesta de un problema planteado a base de certezas, me dispongo a correr un riesgo que pende de algunos hilos (temáticos, figurales, poéticos principalmente), que van apareciendo aquí y allá hasta formar una resonancia imposible de ignorar cuando se (re)conoce la obra de este autor.

\section{Resonancia de la tradición romántica: Rulfo y Elizondo}

Una vez tomada la decisión de alejarse de la pintura y del cine para dedicarse con insistente y obsesivo trabajo a la escritura, la incursión de Elizondo en el escenario de la literatura mexicana nada tiene que ver con los temas y las formas de las letras nacionales. No hay en nuestro autor la menor intención de contribuir, mediante su escritura, a la formación de un modelo de arte nacional. En la entrada del 17 de agosto de 1991, de sus Noctuarios, escribe: "Mis intereses son ahora más lúdicos: me gustan los toros y el béisbol. La literatura mexicana no me interesa mucho. Me interesa el gran arte. El otro no tiene importancia. Quisiera escribir cuentos. Revaloración de algunos escritores de aquí, principalmente Rulfo" (2010: 259). No es que despreciara la escritura de los autores de nacionalidad mexicana, sino que su hilo argumental apuntaba a los siguientes puntos de vista: la genericidad literaria está supeditada a la organicidad propia de la escritura y el criterio de nacionalidad no es suficientemente adecuado para hablar de nuestra literatura, ni en México ni en ningún otro lugar. Tal asunto, Elizondo lo expresó con toda claridad en la entrada del 26 de abril de 1972, de sus Diarios. Es un texto donde expresa la impresión que le causó conocer al ya entonces anciano pintor muralista David Alfaro Siqueiros (1898-1974), y por cuya conversación pudo reflexionar, en la intimidad de su escritura diarística, sobre ciertos asuntos relacionados con la obra y el futuro, la obra y la vida, la obra y la muerte, y la concepción de mundo que es posible forjarse. Cierra la entrada aludida con lo siguiente: "En los dos libros que componen toda la obra de Juan Rulfo no se menciona una sola vez la palabra México" (2015: 228). Sirvan estas dos referencias a la escritura íntima de Salvador Elizondo para hilvanar una idea: reconocer en la escritura de Juan Rulfo la existencia de una propuesta artística notable, que no circunscribe su valor en tanto obra (ni el éxito de su recepción) a la presencia, realista o artificiosa, de una especie de mexicanidad, esencia que de existir variaría de época en época. Es otra cosa lo que admira Elizondo en Rulfo, y es, como sabremos después, la manera en que 
vuelve suyos, abrazándolos desde el español rural que se habla en México, los estilos de otras tradiciones de la expresión artística literaria. Si alargo esta idea, podría decir que es la retórica de la poesía dentro de la narrativa de Rulfo lo que Elizondo atesora y capitaliza en su escritura. La narración, llena de voces sin mediación narrativa, alcanzan su mejor expresión en la soledad enunciadora de la construcción de la espacialidad o de su descripción: el paisaje rulfiano. Volveré más adelante sobre este punto.

Por ahora, en abono a la conjetura anterior, recordemos que en el proyecto que Elizondo sometió a concurso para obtener una de las becas que ofrecía el Consejo Mexicano de Escritores, en 1963, anotó: "La índole de este trabajo podría definirse como un punto medio entre la prosa y la poesía sin ser lo que propiamente se llama «narración poética» ya que el lenguaje que pretendo emplear no trasciende en ningún momento los límites de la prosa" (Aguilar Sosa, 2015 ${ }^{1}$ ). El proyecto referido es la escritura de Farabeuf, que aparecerá en 1965, año en que ganará el Premio Xavier Villaurrutia de Escritores para Escritores. Esa escritura sin definiciones ni limitaciones precisas de genericidad es resultado de la búsqueda de lo único que le es verdaderamente propio a un autor: su estilo. Estilo que ya campeaba en las páginas de "Sila". Cito el íncipit para apreciar el énfasis en la modalidad descriptiva con lo cual se configura un espacio determinado, un lugar, y cómo también, de manera simultánea, se crea a través de una imagen poética el sumario de lo que serán las relaciones entre los personajes que irán apareciendo en el cuento.

"Era de noche cuando llegamos a Sila"

La oscuridad reverberaba con el chirriar luminoso de las cigarras y el polvo se aquietaba bajo el vendaval que descendía de la sierra como por una escalera. Sila, abandonada en medio de la 1lanura, apenas se erguía sobre la tierra despidiendo olor a sangre seca, a antorchas apagadas y a petate ahumado. La vastedad del valle aprisionaba al pueblo con sus tenazas de cielo abierto. El cascabeleo de las serpientes hacía relinchar al Diablo y al Colorado que llenaban con su grito mecánico y óseo el ambiente frío. (Elizondo, 1962: 14)

A propósito de la relación de Juan Rulfo con Salvador Elizondo, particularmente respecto de este cuento, algunos críticos han señalado con énfasis la admiración que el fundador de Sila, el lugar elizondiano, expresó por el fundador de Comala, el lugar rulfiano por excelencia. Se ha subrayado también algunos rasgos comunes, cuya intención artística buscan los críticos dirigir hacia la idea de la imitación, de la emulación como homenaje. Esta idea se sustenta en la presencia acumulada de motivos:

Algunos de ellos son el viaje de retorno del personaje principal (Paulino) a su pueblo en búsqueda del reencuentro con su pasado [...], situación que evoca los pasos de Juan Preciado; el pueblo habitado por las voces de los muertos, como Comala [...]; el personaje del idiota, Jacinto, que

\footnotetext{
${ }^{1}$ Artículo de Yanet Aguilar Sosa publicado en la sección "Cultura" del periódico El Universal, el día 24 de noviembre de 2015 con el siguiente título: "El lugar donde Elizondo dio vida a Farabeuf”. Se cita la versión electrónica del día 25 de mayo de 2018.

${ }^{2}$ En este artículo citaré la versión original de "Sila", publicada en la Revista de la Universidad de México (1962). Las comillas que aparecen en las citas corresponden a esa edición, y cumplen la función, como se sabe, de enfatizar el estilo directo, en el modo de la narración que asume el narrador autodiegético. Es una historia contada en primera persona acompañada por una variedad de voces-eco, que intervienen con un carácter teatral subrayando así un fuerte procedimiento mimético.
} 
evoca la imagen de Macario; las relaciones incestuosas y los conflictos sociales desatados por la posesión de la tierra. (Gutiérrez Piña, 2016: 42)

La crítica analiza la retórica discursiva de los cuentos y traza la cartografía retórica que comparten: diálogos, monólogos internos, flujo de consciencia, fragmentación del tiempo y del espacio, ausencia de la mediación narrativa, confusión o alternancia de voces, de planos narrativos y puntos de enunciación. Hasta aquí vamos de acuerdo. Ya desde este cuento observamos a un autor para quien la imagen (estática o en movimiento) junto con la expresión poética será la forma apropiada para reducir la anécdota y lograr el efecto de un procedimiento reiterativo, ritual. La prosa de Elizondo tiene el ritmo de la poesía y tiene también la potencia semántica que ofrece el discurso tropológico: nada gratuito hay en su escritura.

He recuperado las páginas introductorias que Claudia L. Gutiérrez Piña dedica a este cuento en su libro Las variaciones de la escritura: una lectura crítica de El grafógrafo y la obra de Salvador Elizondo por varias razones: la primera es porque ofrece un fundado parangón entre el cuento de Rulfo y el de Elizondo; la segunda es porque hace una revisión minuciosa sobre la recepción crítica del cuento a la vez que apunta hacia la idea de un disfraz imitativo que en realidad es la búsqueda de una voz propia, no de un estilo — parece sostener la colega. Otra razón para detenerme en el trabajo referido es porque veo posibilidades de abundar en ese tema del estilo (y en el de la poética) que se deja de lado, pero que al mismo tiempo se impone en su negación: hay en "Sila", pienso, algo más que un fantasma del estilo de Salvador Elizondo que hoy, sin duda, nos hace considerarlo un autor clásico. No es que este cuento, "Sila", sea la obra magistral con la cual irrumpe Salvador Elizondo en la literatura (ese lugar le corresponde a Farabeuf), sino que leído en retrospectiva es inevitable reconocer en ese primer cuento algunos de los motivos, temas y recursos discursivos que definirán su estilo poético dentro de la prosa; idea literaria de la que ya era consciente nuestro autor y a la cual dedicó sus largas jornadas de trabajo registradas en sus cuadernos.

\section{Del paisaje realista al paisaje imaginario}

No todo llano es geográficamente ubicable. Hay llanos cuya inmensidad se abisma al paso de los trazos que se dibujan o de las ruinas que vamos dejando: el llano, la llanura; el sitio, la hoja; otros se espacializan, se vuelven habitables: la imagen, la escritura. "Hoy a medio día concebí una idea que tengo que poner aquí: el mar de iguanas", escribió Elizondo en sus Noctuarios (2010) el día 15 de diciembre de 1986. Una imagen que será el título del libro póstumo titulado El mar de iguanas y que contiene la escritura producida durante las horas de la noche.

Algo más hay en "Sila"; algo más hay en su primer parágrafo: "Sila, abandonada en medio de la llanura...". Este llano, en tanto sitio o lugar, es rulfiano: "Emigdio me lo ha dicho. / —Si vas a Sila no encontrarás a nadie, ni nada, nada... sólo a los muertos que andan sueltos" (14); Sila es el infierno al que se baja porque el deseo de recuperar a la amada persiste en la memoria de quien por causas incomprensibles no pudo ser el héroe victorioso y tuvo que autoexiliarse para que su alma sin cuerpo (¿o su cuerpo sin alma?) se encontrara con la nada; ese no espacio donde 
vagan las almas sin reposo, aquellas que no recibieron la debida sepultura y quedaron a merced del viento, de la lluvia y de la rapiña de las aves, cuando no de otros hombres. Son Paulino y Bibiana Monteros los amantes sin amor; es Jacinto, el seductor-acosador-violador de su hermana Bibiana; es Casimiro Gabaldón, el hacendado explotador; Martina, la madre de Paulino; Roque, el pretendiente. Todos conservan el nombre, se reconocen por su voz, la palabra es la única identidad que les queda. Sus voces andan en busca de su forma verdadera; todos los cuerpos se han convertido en uno solo que es el llano. Así es Sila y así es la idea de la escritura que Elizondo despliega en este cuento: el llano es liso, plano, como la hoja en blanco; por sus caminos no dibujados corren fantasmales historias, imágenes transparentes y pesadas, complejas porque para asirlas se precisa comprender el ritual, el proceso cuyo efecto sea coincidente con el deseo y con el sacrificio: he aquí el rito.

Y entonces bajaban los papalotes como peces asidos por un anzuelo presuroso y Bibiana se iba y yo me quedaba solo, a mitad del llano, hurgando en su imagen para encontrar su carne nueva y dura, mordisqueando sus palabras

(-Luego nos vemos, Paulino...)

para sentir sus labios calientes entre mis labios y sus senos redondos latiendo junto a mis orejas.

¿En dónde estás, Bibiana Montes? ¿Moriste tú también? ¿O estás escondida en esta tierra, entre todo esto que es mi recuerdo y mi esperanza?... Bibiana... (14)

Lugar, espacio. El llano, la literatura, el cuerpo, el cuaderno, la hoja, el texto, si se quiere. En tanto paisaje, es decir, en tanto lugar puesto en perspectiva, Sila es un espacio rural, fantasmagórico, abandonado por su gente y habitado tan solo por las almas en pena de quienes dejaron allí algún círculo de vida sin cerrar. Espacio geográfico, pero también espacio literario, escritural, como lo definiera Maurice Blanchot en su L'Espace Littéraire ${ }^{3}$ (1955) y cuya propuesta filosófica, teórica y escritural Elizondo supo introducir en la tradición hispanoamericana cultivada en México, esa que defendía el cruce de tradiciones, o de caminos según un título de ensayos de Juan García Ponce, otro integrante de la llamada Generación del Medio Siglo, para quienes la escritura es el espacio donde el pensamiento cobra forma. Las propuestas estéticas de Elizondo y de García Ponce, lectores ávidos de la literatura y la filosofía centroeuropeas (entre otras), comparten algunas aristas, entre ellas destaco la relacionada con el erotismo y la muerte; la de la erótica del cuerpo penetrado, violentado, mutilado, fragmentado o sacrificado:

No me compadezcas, Paulino. Cuando sentí sus manos hurgando entre mis piernas y sus ojos perdidos tratando de poseerme sentí miedo, pero me dejé vencer. Su boca de niño me besaba los senos y sus brazos fuertes me oprimían la espalda con furia. Sí, tenía la cara manchada de sangre. Yo también vi mi rostro reflejado en sus ojos que eran como dos pozos de sangre y dejé que me

\footnotetext{
${ }^{3}$ En una entrevista, Salvador Elizondo expresó lo siguiente respecto a la influencia que Maurice Blanchot representa para él y sus contemporáneos: "Mi deuda con Bataille es de orden estrictamente formal, iconográfica, de hecho. A Bataille le debo la fotografía del suplicio, publicada en Les larmes d'Eros como documento estético cargado de contenido psicológico capaz de ser convertido en efecto. Por lo que respecta a Blanchot yo creo que casi todos los escritores de mi tiempo estamos en deuda con él. Ha dado a los escritores de mi edad la noción de espacio-tiempo de la escritura. La escritura como fenómeno en el sentido filosófico: algo «que acontece», algo que puede ser observado y, tal vez, descrito" (Hölz, 1995: 123).
} 
tomara con todas sus ganas. Desde entonces ya nunca volví a pensar en ti y sólo pensé en él y lo que más me gustaba era el olor de la sangre de las cabras de todo su cuerpo y quería sentir sus manos pegajosas de sangre deslizarse entre mis piernas y sentir sus ojos como charcos de sangre sobre mi frente para ver mi cara reflejada en ellos... (16)

Mi cuerpo ya no es de nadie, Paulino. Aquella noche me llevaron desnuda hasta el rastro; tu madre iba a mi lado. Ella lo vio todo. Allí tendida entre las cabras muertas, todos ellos... y luego la muerte, lenta y cálida como el placer... (16)

Este mismo principio vertebra la historia de Farabeuf: la delimitación de la muerte y del placer; la destrucción del cuerpo mediante su profanación. Esta es la imagen que sostiene el ritual de la escritura, ritual que leeremos en forma de novela sobre la novela con el nombre de $E l$ hipogeo secreto: un extraño narrador multiplica en su voz y en su escritura las esquinas más recónditas de la realidad, de su pasado, de la ficción misma y las filtra a través del recuerdo y la escritura para destilar con el paso del tempo narrativo una metáfora que será una suerte de poética: "Lo que de la vida perciben los sentidos es como un tropel; un tropel que avanza hasta llegar al borde de ese abismo que somos, lo salva y luego pasa y se desvanece como un demonio exorcizado. Sólo queda en la escritura, en la memoria, el redoblar de los cascos, una resonancia sobre la llanura del cuerpo ¿entiendes?” (2000: 111).

El de Salvador Elizondo no es un espacio tradicional, sino una ruina mental construida verbalmente y de la que los personajes tienen plena consciencia; una ruina construida "de un material hecho de pérdida, un universo cuya esencia es el extravío de todo lo que lo constituye. Allí viven los seres y las cosas que nunca hemos vuelto a ver; lo irrecuperable..." (81); una ciudad "concebida para ser merodeada por dioses silvestres y por los muertos que amamos" (99). El recuerdo, la evocación de un mundo creado o devuelto a partir de la escritura. Así mismo es "Sila": allí está el sacrificio, la sangre, el cuerpo, que encuentran correspondencia en el rito, la tinta y la escritura que va buscándose en la nada, en la blancura del llano: "Veo tu rostro, Bibiana, manchado de sangre, pero no entiendo tus palabras. Quiero verme en tus ojos, pero no me reflejan. Hace frío, Bibiana, quiero cobijarme con tu cuerpo ultrajado, pero no puedo asirlo porque está hecho de sombras..." (16).

El pueblo y su resistencia a ser habitado, los sonidos de la noche, la sensación vacía del abandono y de la violencia que lo provoca; la música estridente de las chicharras y la acústica sonora del movimiento de las serpientes, más la plasticidad corporal y la intensidad de la respuesta asustada de los caballos se acoplan a un mismo ritmo: el de la descripción de un paisaje avistado por alguien que lo reconoce como propio, pero que regresa a él con el sigilo de quien sabe que salió expulsado y aún no rinde las cuentas necesarias por haber cobrado venganza en honor suyo y de la mujer amada. Todo ello en una imagen cinematográfica hecha con palabras; la descripción no es ausencia de narración: es su condensación, la cronología se ha transfigurado en espacialidad, por eso la mirada, un golpe de vista, alcanza para aprehender todo lo que allí sucede.

Sila siempre había sido matadero de cabras, Cuando llegaba el tiempo de la matanza, venían los hombres de las poblaciones vecinas con los rebaños. El rastro entraba en actividad y durante las noches ardían las teas alumbrando la actividad sangrienta de los vecinos de Sila. 
[...] No hay más que sangre... de cabras y de hombres. Sila es algo que se refleja en un charco de sangre y tu rostro que llamo con el pensamiento está manchado de sangre... (15-16)

Elizondo introduce en su escritura el paisaje rulfiano: un paisaje que se mira en su exterioridad pero que cobra sentido únicamente cuando se ha hecho eco de la interioridad de quien acercándose a él lo anula en tanto paisaje y lo convierte en espacio habitable, en vida. La perspectiva, la distancia desaparece porque ya no es más la mirada sino el cuerpo de los objetos y su relación lo que inaugura la espacialidad que los define en cuanto tales. Cuerpos con vida; cuerpos de escritura; escritura y vida. Aquí está, asomándose con peligrosa luz, el espacio literario, esa idea blanchotiana de escribir para no morir.

Ahora bien, sin el vano afán de establecer distingos categóricos entre espacio y paisaje, me gustaría apuntar aquí otra consideración: si bien los paisajes son espacios, estos últimos están hechos para ser habitados, son lugares construidos o transformados en función del movimiento generado por las acciones de los seres que los experimentan de manera vívida; un paisaje, en cambio, más que habitado es percibido; es decir, un paisaje es el lugar que distanciado de su observador puede ser descrito, de allí el hecho de que todo paisaje sea ante todo, y a causa de esta visión panorámica, un espectáculo. La perspectiva que elige esta mirada atenta para describir el paisaje es la encargada de configurar, en la escritura elizondiana de "Sila", un realismo de escritura más que la representación espacial de una forma de realidad. Que los espacios construidos como sitios donde habitan los personajes tengan una carga de ilusión referencial mayúscula no impide que sean también susceptibles de una aprehensión fenoménica similar a la que exige el paisaje natural o urbano; es decir, el lugar donde se realiza una escena, cualquier conversación o incluso un monólogo puede tenerse como paisaje. Sin embargo, solamente la distancia (o la mirada por encima de los propios personajes o de la perspectiva vocal) entre objeto (espacio) y sujeto hará posible la transformación de esos lugares en paisajes. Esta situación de distanciamiento del espacio observado es la que permite su descripción cual si se tratara de una representación mimética. No hay tal, las semejanzas por más abrumadoras que se perciban en relación con los objetos culturales extratextuales tienen su propio y particular modo de existencia en la configuración poética que las contiene.

A la luz de estas cavilaciones, podría sumarse una variación en la geografía mental de Elizondo y considerarla ahora como el resultado de la recuperación memorística del estado onírico, ese tiempo-espacio donde se confabulan la imaginación, el deseo y la creación para dar origen a la única realidad posible: la escritura. Desbordar las fronteras espaciales, transformar lo real en ilusorio y lo imaginario en realista es una marca de la modernidad en la escritura literaria. Ejemplos los hay en abundancia en la tradición que encabezan Baudelaire-Mallarmé y a la que se suman Joyce, Musil, Kafka, Robbe-Grillet y Michel Butor, por citar autores caros a la estética de Elizondo (y a la de Rulfo). Para esta tradición, los espacios no son sino multiplicaciones, a varios niveles, de lugares; ante la desazón provocada por el caos de la modernidad, el espacio adquiere una profunda complicación: es abismo, es laberinto y, sin embargo, continúa siendo expresión de la subjetividad. En tanto paisaje, no hay posibilidad de describir un espacio o una geografía más allá de la experimentación; esto es, el modo en que se siente o se experimenta un lugar, sea 
imaginario o no, sea por parte del sujeto enunciador o a través de los personajes que este dirige, determina la verosimilitud de la configuración espacial.

La escritura de Salvador Elizondo no se funda, entonces, en la observación de un mundo de la realidad, sino en un mundo de la fantasía, de la realidad interior y este no se observa en una realidad dada, no se puede observar así, porque no existe antes de la escritura, más bien tiene lugar únicamente en el espacio creado por la escritura misma. El movimiento, de haberlo, sucede en una suerte de actividad en extremo subjetiva: la escritura; desde esta óptica, por ejemplo, las experiencias de dolor y de alegría, o de amor, son más intensas cuando se experimentan en términos de literatura, es decir, cuando son imaginadas más que cuando son vividas a partir de determinada experiencia exterior. Puedo leer aquí el asomo de la estética del efecto hacia la que Elizondo se dirigió todo el tiempo: prosa y poesía sin desbordarse en prosa poética; una obra donde el rito de la escritura atienda únicamente a la forma como contenido y defina allí su estilo, donde el procedimiento iterativo del ritual produzca el efecto de la sucesión sin que en realidad suceda ese movimiento.

Consciente de la repetición, debo insistir en un punto: no son los paisajes reales o "naturales" los que el lector de Elizondo encontrará en su escritura, son en todo caso paisajes imaginarios, paisajes interiores, oníricos, que para el lector revelan la idea de que el espacio de la escritura es un espacio de expresión de la verdad, que no es lo mismo que decir sinceridad.

"Sila", además de la imagen erótico-infernal del cuerpo ultrajado y de la fuerte imagen del sacrificio de Bibiana como si fuera una más de las cabras, es sobre todo la creación de espacios escriturales sostenidos en un lenguaje tropológico, en el que las imágenes dejan huellas (runas y ruinas) que serán retomadas en textos (cuerpos) posteriores: el llano que es Sila será la llanura del cuerpo de El hipogeo secreto (lugar y novela al mismo tiempo), que será el cuerpo deseado de la institutriz de Elsinore, el Colegio Militar; que seguirá siendo El mar de iguanas, ese inmenso horizonte abierto y luminoso únicamente durante la escritura de la noche.

\section{El espacio íntimo como espacio poético}

Toda escritura comienza en el cuaderno, en el umbral de un destino ajeno, como diría Michel Foucault (1996: 79); en el cuaderno están las entradas de los diarios, la de los noctuarios, allí todo es breve, fragmentario, híbrido: lo que allí se cultiva es un semillero de ideas cuyos brotes son el simuacro de la obra. Para Elizondo, los cuadernos, a diferencia de la autobiografía, representan, o simulan, el espacio de la intimidad primigenia, donde es posible el reconocimiento de sí mismo, y no del hombre literario, como en algún momento pareció sugerirlo al decir: "Ahora ya dejé de ser profesional y gozo cabalmente mi condición de escritor aficionado que se cumple igual que hace 60 años en mis cuadernos en los que sólo guardo, como M. Teste, lo que desearé mañana" (Elizondo, “Cartas desde..."). ${ }^{4}$

\footnotetext{
${ }^{4}$ Estas son las palabras de Elizondo dirigidas a José de la Colina en una carta del 7 de julio del 2003. Desde luego la importancia otorgada a los diarios no es totalmente la del aficionado, pues constantemente, en el diario, Elizondo alude a sus intenciones de publicar los cuadernos, así lo manifiesta el lunes 2 de enero de 1978: "[...] Un proyecto literario interesante: Diarios 1968-1978 para componer durante este año y publicar al final de 78. Un proyecto de
} 
Paradójicamente, la intimidad resguardada en esos cuadernos, cuyo único destino era en apariencia una experiencia interior se convierte simplemente en escritura, o lo que es más, en literatura, al adquirir una dimensión comunicativa que tarde o temprano anula la referencialidad: "He programado mis cuadernos para que sean publicados después de que las cosas de las que hablo en ellos ya hayan sido olvidadas" (citado por García Ramírez). El cuaderno, en tanto cosa pública, quedará convertido en un libro, en el destinatario de lo que está olvidado y constituirá el espacio efectivo de la distancia entre autor y obra. La intención literaria o no de los cuadernos guarda poca importancia, frente a la posibilidad de entrar a formar parte de aquello que se concretará como su obra, previo a lo cual sean los libros, en esa dimensión pública, lo que marcará la entrada a la literatura. ${ }^{5}$

Y ¿qué es un libro?, se pregunta Elizondo en su "Teoría mínima del libro", ese mecanismo misterioso, como él lo llama, adquiere una definición distinta: "El libro es a la vez una máquina, un instrumento y una forma; conlleva la posibilidad de una operación, de una función y de un significado" (2001: 82). El libro, a diferencia del cuaderno, constituye un punto de encuentro al establecerse como la condición de posibilidad de toda lectura. En el cuaderno, en cambio, se reconoce la negación de toda forma y filiación, pues este supone un proceso infinito por el que pasa la escritura sin la codificación de los géneros. Es el lenguaje y el deseo de la escritura lo que prevalece en el cuaderno y en este movimiento azaroso acontece la posibilidad del libro por medio de la constancia del cuaderno.

En la obra de Elizondo, la figura del cuaderno es la que mejor designa el espacio de la escritura en tanto ejercicio, práctica e invocación; frente a la visión acabada y de conjunto que supone el libro, la página en blanco del cuaderno (la llanura del cuerpo) es la inminencia de la escritura inagotable:

Jueves $1^{\circ}$ de enero de 1976. Siempre pasa lo mismo ante la página en blanco. Especialmente cuando es la primera de un cuaderno que se inicia el primer día del año, 1976. Cuántas primicias ocurren en esta conjunción de cosas y de fechas. Quiere decir, tal vez, que estamos al comienzo de algo y no a la mitad, que hay que ponerse a trabajar al alba y aprovechar lo primerizo como si nunca hubiéramos hecho nada hasta ahora. Sólo temprano podemos percibir la realidad como un conjunto simbólico y alegórico que emerge de la tiniebla nocturna a la luz, tal es el caso, por ejemplo, de una mosca que se posa en el cuaderno y revolotea en torno a la pluma mientras voy escribiendo. En ello vemos también la ingente necesidad de cambiar radicalmente la forma de vida en todos los aspectos. Es preciso que a partir de hoy todo sea diferente de como era, nos decimos y sin embargo no podemos dejar de reflexionar; mientras la mano escribe que todo debe ser nuevo, recién nacido, la mente repasa los recuerdos y revive lo que pertenecía al reino del pasado. (2015: 243)

La escritura y la promesa subyacen en el cuaderno, en ese sentido no hay subtítulo más afortunado para Elsinore que el de Un cuaderno. Trabajo que consume la experiencia del diarista

largo alcance en el que hay que conservar únicamente lo que desearemos evocar mañana, como dice el formidable Edmond Teste" ("Tiempo de escritura").

${ }^{5}$ A este respecto es muy significativa la publicación del libro Cuaderno de escritura (1969), el cual se compone de una gran variedad de registros estilísticos: ensayos, notas, apuntes y fragmentos, propios de la hibridez de los escritos que constituyen sus cuadernos. A la vez, este libro es una muestra de la importancia capital que adquiere esta figura en la gestación de la escritura. 
y la del novelista. Despojado de los artificios y de la cerebralidad propia que caracteriza las novelas anteriores, Elsinore se entrega a un deseo propiamente evocativo y sensible. El personaje de esta novela, Salvador Elizondo, recoge las sensaciones y las vivencias de una época de infancia que se sabe perdida y, en esa intimidad, el cuaderno se constituye como el espacio de las memorias y, por tanto, como reinvención del tiempo; el aparente realismo no deja de ser el de la escritura y el sueño desde donde se vuelve a las obsesiones de los textos precedentes con la misma figura del grafógrafo, que también se hace presente: "Estoy soñando que escribo este relato... Me veo escribiendo en el cuaderno como si estuviera encerrado en un paréntesis dentro del sueño" (2001: 9). La evocación de los recuerdos cobra forma en la invocación de los nombres, de la gente y los lugares, pero la evocación, dice Elizondo, como retorno a los orígenes, siempre es incompleta, deficiente. Es un acto inscrito dentro de la temporalidad, y es esto lo que la convierte en hipótesis a posteriori acerca de nuestros orígenes. Elsinore es pues una remembranza de la época perdida en el colegio militar de California, pero Elsinore es también la figura misma del cuaderno que hace posible ese sueño escrito.

Los cuadernos de Salvador Elizondo conforman un eje de relaciones en la gestación de la obra literaria, al develar el movimiento mismo de la escritura: la obsesión elizondiana por excelencia. La escritura de los cuadernos, o diarios, opera por medio de una trasgresión del espacio testimonial para vincularse con la poética especular que el autor cultivó. Este planteamiento tiene su correlato en Autobiografia precoz, tanto como en Elsinore, el "cuaderno", cuyo fundamento novelesco remite a la recodificación de un referente registrado en el diario. El reconocimiento de estos textos en el seno de una filiación literaria autorreflexiva, más que extratextual, pone a la deriva la recurrente oposición entre ficción y realidad en la obra de Salvador Elizondo.

Salvador Elizondo ensaya sobre las huellas que bordean su propio nombre. En esa suma de grafías donde deposita aquello que, en una suerte de efecto proustiano, le permitirá regresar una y otra vez sobre su escritura: la memoria y él mismo. ¿Quién escribe sobre el nombre Salvador Elizondo? ¿Quién dice ese nombre?, ¿a través de qué se dice ese nombre? El nombre es pronunciado, más acá de las grafías, en las huellas sobre las que el nombre de este nombre se va construyendo; sobre todo en el rastro que deja la escritura de Salvador Elizondo. Y es que perseguir ese rastro es recorrer su escritura y recorrerla es no dejar de preguntarnos ¿quién dice algo, no solo acerca del relato, sino acerca de los nombres?

\section{Bibliografía}

AGUILAR SOSA, Yanet: "El lugar donde Elizondo dio vida a Farabeuf". El Universal, México, 24 de noviembre de 2015: http://www.eluniversal.com.mx/articulo/ cultura/letras/2015/11/24/ellugar-donde-elizondo-dio-vida-farabeuf\#imagen-1,15/08/2018.

BLANCHOT, Maurice (2004): El espacio literario. Barcelona, Paidós.

CASTAÑÓN, Adolfo (2010): "Prólogo". En Salvador Elizondo: El mar de iguanas. Girona, Atalanta: 9-27. 
ELIZONDO, Salvador: "Sila". Revista de la Universidad de México XVII/2 (octubre de 1962): 14-16.

--- (1967): Farabeuf o la crónica de un instante. México, Joaquín Mortiz.

--- (1985): La luz que regresa. Antología 1985. México, Fondo de Cultura Económica.

--- (2000): El hipogeo secreto. México, Fondo de Cultura Económica.

--- (2001): Elsinore. Un cuaderno. México, Fondo de Cultura Económica.

---: “Cartas desde y hacia la verandah de Salvador Elizondo”. Letras Libres (Edición México) 89 (mayo de 2006): https://www.letraslibres.com/mexico/cartas-desde-y-hacia-la-verandahsalvador-elizondo, 02/08/2018.

---: “Diarios (1952- 1957). ¿La pintura, el cine o la literatura?”. Letras Libres (Edición España) 79 (abril de 2008): https://www.letraslibres.com/mexico-espana/salvador-elizondo-diarios-19521957-la-pintura-el-cine-o-la-literatura, 02/08/2018.

---: “Los trabajos y los días”. Letras Libres (Edición México) 82 (julio de 2008): https://www.letraslibres.com/mexico-espana/los-trabajos-y-los-dias, 02/08/2018.

---: "Vida literaria" [Diarios 1972-1977]. Letras Libres (Edición México) 116 (agosto de 2008): https://www.letraslibres.com/mexico/vida-literaria, 02/08/2018.

---: “Tiempo de escritura” [Diarios 1977-1980]. Letras Libres (Edición México) 117 (septiembre de 2008): https://www.letraslibres.com/mexico/tiempo-escritura, 02/08/2018.

---: "Regreso a casa" [Diarios 1981-1982]. Letras Libres (Edición México) 86 (noviembre de 2008): https://www.letraslibres.com/mexico-espana/regreso-casa, 02/08/2018.

--- (2009): Autobiografía precoz. México, Aldus.

--- (2010): El mar de iguanas. Girona, Atlanta.

---: “Sila”. Letras Libres (Edición México) 168 (diciembre de 2012): 36-40, https://www.letraslibres.com/mexico/sila, 02/08/2018.

--- (2015): Diarios. 1945-1985. Pról., sel. y notas de Paulina Lavista. México, Fondo de Cultura Económica.

FOUCAULT, Michel (1996): De lenguaje y literatura. Barcelona, Paidós.

GARCÍA RAMÍREZ, Fernando: "Salvador Elizondo: the lonely crab" [Entrevista]. Letras Libres (Edición México) 67 (julio de 2004): https://www.letraslibres.com/mexico/salvador-elizondolonely-crab,02/08/2018.

GUTIÉRREZ PIÑA, Claudia L. (2016): Las variaciones de la escritura: una lectura crítica de El grafógrafo y la obra de Salvador Elizondo. México, El Colegio de México / Universidad Autónoma del Estado de México.

HÖLZ, Karl: "Entrevista con Salvador Elizondo". Iberoamericana 58-59 (1995): 121-126: https://www.jstor.org/stable/41671489, 15/08/2018.

LAVISTA, Paulina: “Los Diarios de Salvador Elizondo”. Letras Libres (Edición España) 77 (febrero de 2008): https://www.letraslibres.com/mexico-espana/los-diarios-salvador-elizondo, 02/08/2018. 
(C) Norma Angélica Cuevas Velasco

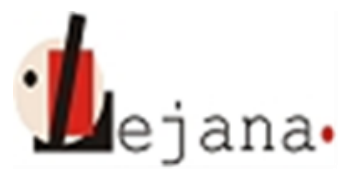

http://ojs.elte.hu/index.php/lejana

Universidad Eötvös Loránd, Departamento de Español, 1088 Budapest, Múzeum krt. 4/C 